\title{
Predictors of Insufficient Sweat Production During Confirmatory Testing for Cystic Fibrosis
}

\author{
Mary Kleyn, MSc, ${ }^{1 \star}$ Steven Korzeniewski, MSc, ${ }^{1}$ Violanda Grigorescu, MD, ${ }^{1}$ \\ William Young, PhD, ${ }^{1}$ Douglas Homnick, MD, ${ }^{2}$ Amy Goldstein-Filbrun, MD, ${ }^{3}$ \\ John Schuen, MD, ${ }^{4}$ and Samya Nasr, $\mathrm{MD}^{3}$
}

\begin{abstract}
Summary. Michigan's Newborn Screening (NBS) Program began statewide screening for cystic fibrosis (CF) in October 2007. Confirmatory sweat testing is performed in infants having initial immunoreactive trypsinogen concentrations $\geq 99$.8th percentile or $\geq 96$ th percentile and at least one CF mutation identified by DNA analysis. Some infants fail to produce a sufficient quantity of sweat (QNS - quantity not sufficient) to test for CF, meaning disease confirmation is delayed and sweat testing is later repeated. In this study, we evaluate predictors of QNS results. Information from the linked birth certificates and NBS diagnostic confirmation data were used. The study population was resident infants born in Michigan in 2008 who underwent a sweat test. Bivariate analyses revealed that preterm birth, low birth weight, CF care center, and race were significantly associated with QNS sweat testing results. Adjusted analyses indicated that preterm infants were 2.4 times more likely to have QNS results $(95 \% \mathrm{Cl} 0.9,6.4)$. When age at time of test, accounting for gestational age (gestational age at delivery plus postdelivery age of life=corrected age), was used in the multivariable model, infants $<39$ weeks were 7.4 times more likely to have QNS results $(95 \% \mathrm{Cl} 2.5,21.8)$. Waiting to sweat test until an infant is aged 39 weeks or more (corrected age) would likely reduce the rate of QNS results, thereby reducing the burden of repeat sweat testing on families and healthcare providers. Further research is necessary to understand the impact of potential delays in diagnosis/treatment relative to postponing sweat testing. Pediatr Pulmonol. 2011; 46:23-30. ๑ 2010 Wiley-Liss, Inc.
\end{abstract}

Key words: quantity not sufficient; preterm infants; newborn screening.

Funding source: Restricted Funding, Newborn Screening Fees.

\section{INTRODUCTION}

Cystic fibrosis $(\mathrm{CF})$ is an autosomal recessive disorder caused by mutations of the $\mathrm{CF}$ transmembrane conductance regulator (CFTR) gene. ${ }^{1}$ Newborn screening (NBS) for $\mathrm{CF}$ has been associated with significant improvements in health outcomes compared to the traditional clinical diagnosis of the disease and is considered a cost-effective public health program. ${ }^{2-4}$ In 2004, the Centers for Disease Control and Prevention, in collaboration with the CF Foundation, reviewed available data and concluded that "the magnitude of the health benefits from screening for $\mathrm{CF}$ is sufficient that states should consider including routine NBS for CF in conjunction with systems to ensure access to high-quality care." ${ }^{.5}$ In 2005, the American College of Medical Genetics NBS Expert Group released an executive summary supporting the addition of $\mathrm{CF}$ to the recommended NBS core panel disorders. ${ }^{6}$

Michigan's NBS Program began screening for CF in October 2007. Michigan (MI) follows an immunoreactive trypsinogen (IRT)/DNA protocol to identify infants potentially at risk for CF. Confirmatory sweat testing for $\mathrm{CF}$ is performed in infants having initial IRT concentrations $\geq 96$ th percentile and at least 1 of $40 \mathrm{CF}$ mutations identified by DNA analysis. Infants without an identified CF mutation having IRT concentrations

\footnotetext{
${ }^{1}$ Michigan Department of Community Health, Lansing, Michigan.

${ }^{2}$ Kalamazoo Center for Medical Studies Cystic Fibrosis Center, Kalamazoo, Michigan.

${ }^{3}$ University of Michigan Cystic Fibrosis Center, Ann Arbor, Michigan.

${ }^{4}$ DeVos Cystic Fibrosis Care Center, Grand Rapids, Michigan.

*Correspondence to: Mary Kleyn, MSc, 201 Townsend Street, P.O. Box 30195, Lansing, MI 48909. E-mail: kleynm@michigan.gov
}

Received 13 November 2009; Revised 26 April 2010; Accepted 29 April 2010.

DOI 10.1002/ppul.21318

Published online 1 September 2010 in Wiley Online Library

(wileyonlinelibrary.com). 
$\geq 99.8$ th percentile were also referred for sweat testing during the first year of NBS for CF in MI.

The sweat test has been the "gold standard" for diagnosis of CF since di Sant'Agnese et al. ${ }^{7}$ observed that patients with $\mathrm{CF}$ have higher sweat chloride concentrations. That discovery was followed by the development of a quantitative pilocarpine iontophoresis test to measure the concentration of electrolytes in sweat in CF patients. ${ }^{8}$ Although sweat testing remains the gold standard for diagnosis, some infants fail to produce a sufficient quantity of sweat (QNS-quantity not sufficient) to perform the sweat testing in the first several weeks of life. The QNS result necessitates a repeat test at a later date, which leads to delay in the confirmation of disease.

The CF Foundation has placed importance on minimizing QNS results and has established several guidelines regarding the conduct of sweat testing for infants. The Foundation recommends sweat testing when an infant is at least 2 weeks of age and weighs $>2 \mathrm{~kg} ;{ }^{9}$ however, it is still unknown whether weight and age at test are the best predictors of QNS results. Characteristics such as "postmenstrual age" (defined as gestational age plus age at sweat test) $<36$ weeks, race, and skin condition have been associated with QNS sweat testing results. ${ }^{10,11}$ The CF Foundation has also set sweat testing standards for CF Foundation accredited care centers; ${ }^{12}$ for patients older than 3 months of age, a center's QNS rate should not exceed $5 \%$. As more states initiate NBS for CF, infants are being identified and referred for sweat testing before 3 months of age. Recently, the CF Foundation added a new standard that a center's QNS rate should be $\leq 10 \%$ for patients 3 months of age or younger. ${ }^{12}$ While these target QNS rates have been achieved in NBS Programs, few of the infants in these studies underwent sweat testing during the first few weeks of life. ${ }^{13-15}$ A study of infants undergoing sweat tests before 6 weeks of age had an overall QNS rate of $26 \%,{ }^{10}$ which does not meet the CF Foundation guidelines.

In MI, approximately $86 \%$ of infants referred for confirmatory sweat testing following a positive NBS are sweat tested during the first 6 weeks of life. Based on the higher QNS rate seen in Eng et al.'s ${ }^{10}$ study population, we hypothesized that the QNS rate in MI would also exceed the CF Foundation guideline of $<10 \%$ due to the number of infants undergoing sweat testing at a very young age. We conducted this study in a population-based cohort of all infants identified by NBS in MI and referred for confirmatory sweat testing to address the following objectives: (1) determine the QNS rate in MI (i.e., a population of young infants undergoing sweat testing); (2) evaluate predictors of insufficient sweat production during confirmatory testing; and (3) use the results of the evaluation of predictors to devise a quality improvement strategy to reduce the
QNS rate in neonates in order to meet the CF Foundation guidelines.

\section{MATERIALS AND METHODS}

This is a retrospective population-based cohort study of predictors of insufficient sweat production during NBS confirmatory testing for CF. NBS commences when blood spots are obtained from all newborns born in MI via a heel prick between 24 and $36 \mathrm{hr}$ of life. Blood spots, along with infant and maternal demographic and perinatal characteristics, are stored on filter paper cards. The cards are sent to the Division of Chemistry and Toxicology housed within the State Laboratory at the Michigan Department of Community Health for analysis. Initial screening data are stored in a Laboratory Information Management System (LIMS) created by Perkin Elmer Life Sciences, Inc. (Waltham, MA). Confirmatory testing and medical management data, including sweat test results, presence of meconium ileus, and diagnoses, are managed by the NBS Follow-up Program. Sweat tests were performed at one of five CF Foundation accredited care centers in MI.

CF care centers in MI employ two different methods of sweat testing. Three centers use pilocarpine iontophoresis to stimulate sweat production and collect the sweat on gauze pads. QNS is defined as collecting $<75 \mathrm{mg}$ of sweat in a 30-min period. The other two centers use the Wescor Macroduct $^{\mathbb{R}}$ Sweat Stimulation and Sweat Collection system. For this system, QNS is defined as $<15 \mu l$ of sweat in a 30-min period. A study assessing the two methods found no difference between sodium and chloride concentration results obtained from the Macroduct system and from pilocarpine iontophoresis, though the Macroduct system was associated with higher QNS rates. ${ }^{16}$ Both methods of sweat chloride testing are CF Foundationapproved for use for accredited CF care centers and follow the protocol from the Clinical Laboratory Standards Institute. $^{17}$

In MI, NBS and live births records are routinely linked to identify potentially unscreened infants. ${ }^{18}$ Typically, $99 \%$ or more of the births records are successfully matched to newborn screens. Due to the reliability of demographic and perinatal characteristics on birth certificates $^{19}$ and fewer missing variables, we chose to use birth weight, gestational age, race, sex, and multiple birth status from the linked birth certificates rather than from NBS cards. In addition, medical management data including meconium ileus status, CF care center, sweat test method, sweat test results, and age at test were also used. Birth weight and gestational age were assessed as both continuous and categorical variables. Gestational age was categorized as $<35$ weeks, 35-36 weeks, and $\geq 37$ weeks. Low birth weight was defined as $<2,500 \mathrm{~g}$. Two measures of age at time of sweat test were used. 
The first measure was age at time of sweat test. The second measure of age (corrected age) was adjusted for gestational age by adding gestational age to postdelivery age at the time of sweat test. We used the second measure of age to account for the potential impact of prematurity on QNS results. This corrected measure of age was included as a continuous predictor of QNS results in a bivariate logistic regression model. We obtained the regression equation and used it to determine the age (in weeks) that was no longer associated with increased odds of QNS results (i.e., where the odds of QNS results crossed unity). We entered corrected age of 32 weeks in the regression equation, calculated the coefficient, and exponentiated the coefficient to determine the odds of QNS results at that age. We repeated this process, each time adding 1 week to the corrected age. The age where the odds of QNS become smaller than one was considered the appropriate age to dichotomize this second measure of age.

Resident infants born in MI between January 1, 2008 and December 31, 2008 who underwent sweat testing were included. Only the initial sweat test results were used.

Data analysis was performed using SAS version 9.1 (SAS Institute, Inc., Cary, NC). Bivariate analysis was conducted using the following variables: age at time of sweat test, birth weight, gestational age, race, sex, CF care center, sweat test method, meconium ileus, multiple birth status, and corrected age at time of sweat test. Potential interactions were also tested. Multivariable analyses assessing predictors of QNS results included all variables significantly associated with QNS results in the bivariate analysis as covariates. An alpha of 0.05 was used for this study.

\section{RESULTS}

Overall, 119,327 resident infants born in 2008 were screened for $\mathrm{CF}$ and 315 infants underwent sweat testing. The mean age at time of sweat test was 26.4 days and the median was 20 days (range $4-159$ days). Of the 315 infants, $63(20 \%)$ had QNS results. Approximately $12.5 \%(\mathrm{n}=39)$ of the infants who had a sweat test were born preterm. Of those 39 preterm infants, 19 had QNS results. The QNS rate among preterm infants was three times the QNS rate among term infants (49\% and $16 \%$, respectively).

The association between QNS results and categorical gestational age was assessed. The odds of QNS results for infants $<35$ weeks were similar to the odds for infants 35-36 weeks (OR $=6.1,95 \%$ CI $2.1,17.8$ and $\mathrm{OR}=4.5,95 \%$ CI $1.9,10.8$, respectively). Due to the significantly increased odds of QNS results for both categories of preterm infants, gestational age was dichotomized and preterm birth was defined as $<37$ weeks gestation.

Bivariate analyses revealed that preterm birth, low birth weight, CF care center, and race were significantly associated with QNS sweat testing results (Table 1). Although CF care center was significantly associated with QNS results, method of sweat collection was not. Thus, CF care center was retained and method of sweat collection was not included in multivariable models.

Both gestational age and birth weight were assessed categorically and continuously. For every 1 -week increase in gestational age, the odds of QNS results decreased nearly $30 \%(\mathrm{OR}=0.7,95 \%$ CI $0.6,0.8)$. For every $1 \mathrm{~kg}$ increase in birth weight, the odds of QNS results decreased $70 \%(\mathrm{OR}=0.3,95 \%$ CI $0.2,0.5)$. None of the tested interactions were significant and were excluded from subsequent models.

Adjusted analyses indicated that preterm infants were approximately 2.5 times more likely to have QNS results $(\mathrm{OR}=2.4,95 \% \mathrm{CI} 0.9,6.4)$ relative to term infants though the association was not significant (Table 2). Low birth weight infants were four times more likely to have QNS results $(\mathrm{OR}=4.2,95 \% \mathrm{CI} 1.5,11.7)$ compared to normal birth weight infants. One CF care center had significantly increased odds of QNS results $(\mathrm{OR}=3.2,95 \%$ CI 1.0, 9.9). After adjustment, race was no longer significantly associated with QNS results. The Hosmer and Lemeshow goodness-of-fit test for this model had a $P$-value of 0.18 , indicating that this model is a good fit.

When corrected age at time of test was included as a continuous variable in a bivariate model, the odds of QNS results crossed unity at approximately 38 weeks (Table 3 ). Thus, corrected age was dichotomized as $<39$ weeks and $\geq 39$ weeks.

Age at time of test, measured as postdelivery day of life, was not associated with QNS results (Table 1). However, corrected age was significantly associated with QNS results. Infants aged $<39$ weeks at time of test were 7.4 times more likely to have QNS $(95 \%$ CI $2.5,21.8)$ and low birth weight infants were 4.9 times more likely to have QNS results (95\% CI 2.0, 11.9) (Table 4). Again, one CF care center had significantly increased odds of QNS results, and race was no longer significantly associated with QNS results. The Hosmer and Lemeshow goodnessof-fit test for this model had a $P$-value of 0.42 . The $P$-value for this model with corrected age is higher than the $P$-value for the model with gestational age, indicating that the model with corrected age fits the data better. Approximately $7 \%$ of infants were aged $<39$ weeks at time of sweat test (corrected age); of those, $14(66.7 \%)$ had QNS results. The QNS rate among infants $<39$ weeks of corrected age was four times the rate among infants 39 weeks of age or older (67\% and $16 \%$, respectively).

Adding gestational age to the model slightly attenuated the associations, but infants $<39$ weeks of corrected age at time of test and low birth weight infants were still significantly more likely to have QNS results (Table 5). The Hosmer and Lemeshow goodness-of-fit test for this model had a $P$-value of 0.21 . 
TABLE 1-Demographic and Perinatal Characteristics of Infants With Sweat Tests and Predictors of QNS Sweat Tests, Michigan 2008 ${ }^{1}$

\begin{tabular}{|c|c|c|c|c|c|c|}
\hline \multirow[b]{2}{*}{ Demographic } & \multicolumn{2}{|c|}{ Infants with sweat tests } & \multicolumn{2}{|c|}{ Infants with QNS } & \multicolumn{2}{|c|}{ Unadjusted } \\
\hline & $\mathrm{N}$ & $\%$ & $\mathrm{~N}$ & $\%$ & OR & $95 \% \mathrm{CI}$ \\
\hline \multicolumn{7}{|l|}{ Age at test } \\
\hline$<14$ days & 82 & 26.0 & 23 & 36.5 & 1.6 & $0.8,3.4$ \\
\hline 14-29 days & 150 & 47.6 & 24 & 38.1 & 0.8 & $0.4,1.6$ \\
\hline $30+$ days & 83 & 26.4 & 16 & 25.4 & 1.0 & \\
\hline \multicolumn{7}{|c|}{ Birth weight $(\mathrm{g})^{2}$} \\
\hline$<2,500$ & 31 & 9.9 & 18 & 29.0 & 7.5 & $3.4,16.4$ \\
\hline$\geq 2,500$ & 282 & 90.1 & 44 & 71.0 & 1.0 & \\
\hline \multicolumn{7}{|c|}{ Gestational age (weeks) ${ }^{2}$} \\
\hline$<37$ & 39 & 12.5 & 19 & 30.7 & 5.1 & $2.5,10.4$ \\
\hline$\geq 37$ & 274 & 87.5 & 43 & 69.3 & 1.0 & \\
\hline \multicolumn{7}{|l|}{$\operatorname{Race}^{2}$} \\
\hline White & 247 & 78.9 & 43 & 69.4 & 1.0 & \\
\hline Black & 58 & 18.5 & 17 & 27.4 & 2.0 & 1.0, 3.8 \\
\hline Other & 8 & 2.6 & 2 & 3.2 & 1.6 & $0.3,8.1$ \\
\hline \multicolumn{7}{|l|}{$\operatorname{Sex}^{2}$} \\
\hline Female & 159 & 50.8 & 35 & 56.4 & 1.3 & $0.8,2.3$ \\
\hline Male & 154 & 49.2 & 27 & 43.6 & 1.0 & \\
\hline \multicolumn{7}{|l|}{ Meconium } \\
\hline Yes & 8 & 2.5 & 3 & 4.8 & 2.5 & $0.6,10.6$ \\
\hline No & 307 & 97.5 & 60 & 95.2 & 1.0 & \\
\hline \multicolumn{7}{|l|}{ Multiple birth ${ }^{2}$} \\
\hline Multiple & 7 & 2.2 & 3 & 4.8 & 3.1 & $0.7,14.4$ \\
\hline Singleton & 306 & 97.8 & 59 & 95.2 & 1.0 & \\
\hline \multicolumn{7}{|c|}{ Sweat test method ${ }^{2}$} \\
\hline Pilocarpine & 140 & 44.7 & 24 & 39.3 & 1.0 & \\
\hline Macroduct & 173 & 55.3 & 37 & 60.7 & 1.3 & $0.7,2.3$ \\
\hline \multicolumn{7}{|c|}{ Corrected age at test (weeks) ${ }^{2}$} \\
\hline$<39$ & 21 & 6.7 & 14 & 22.6 & 10.2 & $3.9,26.5$ \\
\hline$\geq 39$ & 292 & 93.3 & 48 & 77.4 & 1.0 & \\
\hline \multicolumn{7}{|c|}{ CF Care Center ${ }^{2}$} \\
\hline $\mathrm{A}^{3}$ & 27 & 8.6 & 8 & 13.1 & 3.0 & $1.0,8.6$ \\
\hline $\mathrm{B}^{4}$ & 70 & 22.4 & 17 & 27.9 & 2.3 & $1.0,5.4$ \\
\hline $\mathrm{C}^{3}$ & 81 & 25.9 & 10 & 16.4 & 1.0 & \\
\hline $\mathrm{D}^{3}$ & 32 & 10.2 & 6 & 9.8 & 1.6 & $0.5,5.0$ \\
\hline$E^{4}$ & 103 & 32.9 & 20 & 32.8 & 1.7 & $0.8,3.9$ \\
\hline
\end{tabular}

${ }^{1}$ Bold type indicates $P$-value $<0.05$.

${ }^{2}$ Missing data on two infants.

${ }^{3}$ Sweat test method is pilocarpine iontophoresis.

${ }^{4}$ Sweat test method is the Wescor Macroduct ${ }^{\mathbb{R}}$ Sweat Stimulation and Sweat Collection system.

\section{DISCUSSION}

Our study indicates that age at time of the sweat chloride test, accounting for gestational age, is one of the driving predictors of QNS rates. It may be appropriate for clinicians to wait until preterm infants screening positive for $\mathrm{CF}$ reach 39 weeks of corrected age prior to sweat testing to reduce the QNS rate and associated repeat sweat tests. However, further research is necessary to confirm the results of this study in larger patient populations and to evaluate the potential impact of delays in treatment derivative of implementation of this recommendation.

Confirmatory sweat chloride testing is considered the "gold standard" for the diagnosis of CF. Those advocating sweat testing soon after initial NBS results are available postulate that the benefits of early identification outweigh the risk of obtaining a QNS sweat test. ${ }^{15}$ However, if a sufficient quantity of sweat cannot be collected, the test must be repeated at an average cost of $\$ 161.40$, resulting in increased time and cost for both the families and the healthcare system. ${ }^{4}$ Furthermore, sweat testing is a stressor for both the infant and his/her family relative to other confirmatory tests in NBS. While the number of sweat tests is not a major factor in parental stress, a QNS result will cause a delay in the time to diagnosis since the sweat test will need to be repeated at a later date. In our study population, the average time from the initial insufficient sweat test result to the diagnosis date was 45 days, with a median of 32 days. Although a slight delay may occur before the sweat test while waiting for preterm 
TABLE 2-Adjusted Associations Between Demographic and Perinatal Characteristics, Gestational Age, and QNS Sweat Test Results, Michigan $2008^{1}$

\begin{tabular}{|c|c|c|}
\hline \multirow[b]{2}{*}{ Characteristic } & \multicolumn{2}{|c|}{ Adjusted $^{2}$} \\
\hline & OR & $95 \% \mathrm{CI}$ \\
\hline \multicolumn{3}{|l|}{ Birth weight (g) } \\
\hline$<2,500$ & 4.2 & $1.5,11.7$ \\
\hline$\geq 2,500$ & 1.0 & \\
\hline \multicolumn{3}{|c|}{ Gestational age (weeks) } \\
\hline$<37$ & 2.4 & $0.9,6.4$ \\
\hline$\geq 37$ & 1.0 & \\
\hline \multicolumn{3}{|l|}{ Race } \\
\hline White & 1.0 & \\
\hline Black & 1.3 & $0.6,3.0$ \\
\hline Other & 0.6 & $0.1,6.2$ \\
\hline \multicolumn{3}{|l|}{ CF Care Center } \\
\hline A & 3.2 & $1.0,9.9$ \\
\hline B & 2.2 & $0.9,5.5$ \\
\hline $\mathrm{C}$ & 1.0 & \\
\hline $\mathrm{D}$ & 1.5 & $0.5,5.0$ \\
\hline $\mathrm{E}$ & 1.6 & $0.6,4.0$ \\
\hline
\end{tabular}

${ }^{1}$ Bold type indicates $P$-value $<0.05$.

${ }^{2}$ Adjusted for all other variables in the table.

infants to reach 39 weeks of corrected age, the time from initial sweat test to diagnosis should be reduced for many of these infants.

Identifying predictors of QNS results may allow for a more accurate algorithm concerning the timing of a sweat test. Similar to our findings that the postdelivery age at sweat test was not associated with increased likelihood of QNS results, two studies found no significant difference in the rates of QNS results for infants $<6$ weeks of age compared to infants $>6$ weeks of age ${ }^{13}$ or by increasing week of life after 2 weeks of age for CF NBS-positive newborns. ${ }^{15}$ Neither of these studies considered the influence of gestational age on sweat test results.

Other studies have examined the association between gestational age and rates of QNS. Harpin and Rutter ${ }^{20}$ found that babies $<36$ weeks gestation did not sweat on the first day of life when exposed to heat, but by 13 days

TABLE 3-Odds of QNS Sweat Tests by Corrected Age (in Weeks), Michigan 2008

\begin{tabular}{lc}
\hline Corrected age & Odds of QNS sweat tests \\
\hline 32 & 9.21 \\
33 & 6.30 \\
34 & 4.32 \\
35 & 2.96 \\
36 & 2.02 \\
37 & 1.39 \\
38 & 0.95 \\
39 & 0.65 \\
40 & 0.44 \\
41 & 0.30 \\
42 & 0.21 \\
\hline
\end{tabular}

TABLE 4-Adjusted Associations Between Demographic and Perinatal Characteristics, Corrected Age, and QNS Sweat Test Results, Michigan $2008^{1}$

\begin{tabular}{|c|c|c|}
\hline \multirow[b]{2}{*}{ Characteristic } & \multicolumn{2}{|c|}{ Adjusted $^{2}$} \\
\hline & OR & $95 \% \mathrm{CI}$ \\
\hline \multicolumn{3}{|l|}{ Birth weight (g) } \\
\hline$<2,500$ & 4.9 & 2.0, 11.9 \\
\hline$\geq 2,500$ & 1.0 & \\
\hline \multicolumn{3}{|c|}{ Corrected age (weeks) ${ }^{3}$} \\
\hline$<39$ & 7.4 & $2.5,21.8$ \\
\hline$\geq 39$ & 1.0 & \\
\hline \multicolumn{3}{|l|}{ Race } \\
\hline White & 1.0 & \\
\hline Black & 1.7 & $0.7,3.7$ \\
\hline Other & 0.8 & $0.1,7.4$ \\
\hline \multicolumn{3}{|l|}{ CF Care Center } \\
\hline A & 3.4 & $1.1,10.9$ \\
\hline B & 1.8 & $0.7,4.7$ \\
\hline $\mathrm{C}$ & 1.0 & \\
\hline $\mathrm{D}$ & 1.6 & $0.5,5.6$ \\
\hline $\mathrm{E}$ & 1.6 & $0.6,4.1$ \\
\hline
\end{tabular}

${ }^{1}$ Bold type indicates $P$-value $<0.05$.

${ }^{2}$ Adjusted for all other variables in the table.

${ }^{3}$ Defined by adding gestational age and age at time of test.

all babies (term and preterm) were able to sweat. Other studies have confirmed that it is more difficult to obtain sweat chloride in babies on the first day of life and that preterm babies are over-represented in the group of infants

TABLE 5-Adjusted Associations Between Demographic and Perinatal Characteristics, Gestational Age, Corrected Age, and QNS Sweat Test Results, Michigan $2008^{1}$

\begin{tabular}{|c|c|c|}
\hline \multirow[b]{2}{*}{ Characteristic } & \multicolumn{2}{|c|}{ Adjusted $^{2}$} \\
\hline & OR & $95 \% \mathrm{CI}$ \\
\hline \multicolumn{3}{|c|}{ Birth weight (g) } \\
\hline$<2,500$ & 4.6 & $1.6,13.5$ \\
\hline$\geq 2,500$ & 1.0 & \\
\hline \multicolumn{3}{|c|}{ Gestational age (weeks) } \\
\hline$<37$ & 1.1 & $0.4,3.5$ \\
\hline$\geq 37$ & 1.0 & \\
\hline \multicolumn{3}{|c|}{ Corrected age (weeks) ${ }^{3}$} \\
\hline$<39$ & 7.0 & $2.1,23.2$ \\
\hline$\geq 39$ & 1.0 & \\
\hline \multicolumn{3}{|l|}{ Race } \\
\hline White & 1.0 & \\
\hline Black & 1.6 & $0.7,3.7$ \\
\hline Other & 0.8 & $0.1,7.4$ \\
\hline \multicolumn{3}{|l|}{ CF Care Center } \\
\hline A & 3.4 & $1.1,11.0$ \\
\hline $\mathrm{B}$ & 1.9 & $0.7,4.9$ \\
\hline $\mathrm{C}$ & 1.0 & \\
\hline $\mathrm{D}$ & 1.7 & $0.5,5.6$ \\
\hline $\mathrm{E}$ & 1.6 & $0.6,4.1$ \\
\hline
\end{tabular}

${ }^{1}$ Bold type indicates $P$-value $<0.05$.

${ }^{2}$ Adjusted for all other variables in the table.

${ }^{3}$ Defined by adding gestational age and age at time of test. 
with lower amounts of sweat produced. ${ }^{21}$ However, a study in Tuscany found no significant correlations between age at sweat testing and chloride concentration, age at sweat testing and quantity of sweat collected, birth weight and chloride concentration, or gestational age and chloride concentration. ${ }^{14}$ The discrepancy between our finding that gestational age $<37$ weeks was a predictor of QNS result and the results from the Tuscany study is likely explained by differing distributions of postdelivery age at time of test. In our study, nearly three quarters of the infants underwent a sweat test before 30 days of life. In comparison, only $4 \%$ of the infants in the Tuscany study had a sweat test before 30 days of life. Since the Italian infants were older, gestational age was less likely to influence QNS rates.

Eng et al. ${ }^{10}$ assessed "postmenstrual age" of infant at sweat test defined as gestational age plus age of life at time of sweat test and found that infants aged $<36$ weeks were more likely to have QNS results when adjusted for other demographic factors. Eng et al.'s study was conducted at a tertiary CF center, and 103 infants were sweat tested over a 10 -year period. Thus, the study conducted by Eng et al. was geared towards a specific group of infants and was not designed to be generalizable to statewide populations of infants undergoing confirmatory sweat testing following a positive newborn screen. This present study used a population-based approach to assess predictors of QNS results, so the intent was slightly different from Eng et al.'s. The use of a population-based approach in this present study may lead to findings with greater external validity relative to those of Eng et al.'s study.

Eng et al. ${ }^{10}$ also found that African-American race was associated with significantly higher QNS rates in both unadjusted and adjusted models. This finding differs from the results of the present study which found black infants had increased odds of QNS results in the unadjusted model only. In this present study, the addition of gestational age to the model attenuated the association between black race and increased odds of QNS results. The racial compositions of the study populations were similar: black infants comprised $16.5 \%$ of the study population in Eng et al.'s study and $18.5 \%$ of the study population in this study. Race was categorized as white, black, and other in this study, whereas Eng et al. did not specify if infants of "Other" race were included. However, similar findings were obtained in this study when infants of "Other" race were excluded. More than half of African-American infants in Eng et al.'s study had QNS results (58.82\%) compared to fewer than one-third in the present study (29.3\%). The finding that African-American infants in Eng et al.'s study had twice the QNS rates of AfricanAmerican infants in the present study may contribute to the discrepant race findings between the two studies. Further research is needed to clarify the effect of race on sweat production.
The CF Foundation recommends that CF centers strive to maintain a QNS rate of $10 \%$ or lower for sweat tests conducted among patients younger than 3 months of age. In this study, fewer than $3 \%$ of the infants were older than 12 weeks of age at the time of sweat test. The overall QNS rate was 20\%, and the center-specific QNS rates ranged from $12.3 \%$ at Center C to $29.6 \%$ to Center A. The QNS rate among infants $<39$ weeks of corrected age was four times the rate among infants 39 weeks of age or older (67\% and $16 \%$, respectively).

We searched the literature to compare the QNS rates in MI to the QNS rates of other state NBS programs. However, we found a dearth of information regarding QNS rates across state NBS programs. To the best of our knowledge, we found only one study that listed QNS rates from a population of infants in the United States referred for confirmatory sweat testing following a positive newborn screen. ${ }^{15}$ In that study, the QNS rate was $17 \%$ for sweat tests conducted during the first 2 weeks of life. MI had a $28 \%$ QNS rate among sweat tests conducted during the first 2 weeks of life. Although MI's QNS rate is higher, a QNS rate of $28 \%$ among sweat tests conducted within the first 2 weeks of life is within the $95 \%$ confidence interval in Parad et al.'s study. We encourage other state NBS programs to evaluate their QNS rates, so more information will be available regarding the QNS rates, particularly among young infants, and more quality improvement strategies can be explored.

Other studies have presented QNS rates, but those studies differed from this present study in key areas, making direct comparisons in QNS rates difficult. Farrell and $\mathrm{Koscik}^{13}$ had a QNS rate of $0.7 \%$. In that study of 725 infants undergoing sweat testing, $33.7 \%$ of the infants were referred through a mechanism other than NBS. The mean age at sweat test ranged from 9.3 to 21 weeks. In our study, the mean age at sweat test was 3.8 weeks, and approximately $6 \%$ of the infants underwent sweat testing after 9.3 weeks of age. Lastly, QNS was defined as collecting $<50 \mathrm{mg}$ of sweat, which was the guideline at the time Farrell and Koscik conducted the study. In our study, QNS was defined as collecting $<75 \mathrm{mg}$ of sweat. Taccetti et al. ${ }^{14}$ found a QNS rate of $7.1 \%$ among infants in Tuscany referred from NBS. The average age at time of sweat test in this study was 65 days, compared to 26 days in the present study. Eng et al. ${ }^{10}$ had an overall QNS rate of $26.2 \%$, which is slightly higher than our overall QNS rate of $20.0 \%$. The study did not state whether the infants were referred for sweat testing following a positive newborn screen. Additionally, the sweat testing was conducted before the infants were 6 weeks of age, making the timing the most comparable to our study since $86.4 \%$ of the MI infants had the sweat test conducted before reaching 6 weeks of age. In summary, differences in referral method, average age at time of sweat test, and QNS definition between these previous 
studies and our study may contribute to the range of QNS rates observed.

The present study adds to understanding regarding predictors of QNS results using a population-based cohort of infants identified through NBS. A limitation of this study is the influence of missing or potentially inaccurate data. However, the use of live births records data reduced the number of missing variables and the rate of missing data does not differ by QNS results, so it is unlikely that the study results are affected.

Although many factors can affect sweat chloride concentrations, including hyponatremia from any cause, ectodermal dysplasia, and hypothyroidism, sweat volume seems to be primarily determined by sweat rate during the collection period. In the otherwise normal, healthy infant, two factors are likely causes of insufficient sweat: dehydration and neurologic immaturity. Allowing 2 weeks after birth before sweat testing to establish a feeding pattern with normal amounts of fluid and electrolytes has been a prudent recommendation to reduce QNS rates due to relative dehydration. However, neurologic maturity can change substantially between late prematurity and term with measurable differences in indices such as passive tone and sucking reflex. ${ }^{22}$ Heart rate variability, a measure of autonomic nervous system function, increases significantly during late gestation and is an indication of increasing parasympathetic activity. ${ }^{23,24}$ It is therefore possible that the parasympathetic function of sweat glands likewise matures with increasing gestational age, enhancing the ability of pilocarpine (a muscarinic, M3 receptor agonist) to more consistently stimulate adequate volumes of sweat for chloride determination.

All of the above support the translation of our findings into a recommendation to wait until preterm infants reach "term" (37 weeks) plus the 2 weeks that the CF Foundation advises (39 weeks of age in total) prior to performing a sweat test. The waiting period will be longer for very preterm infants, but once the "term" age has been achieved, infants will be less likely to experience QNS results. Thus, the suggested translation of our study findings is in sync with and complementary to the current CF Foundation recommendation of sweat testing when an infant is at least 2 weeks of age. Our study indicates that the CF Foundation's guideline is most effective for term infants, so preterm infants will need to reach the minimum "term" age (37 weeks) before the 2-week waiting period begins.

The findings from this study suggest that weight at test and postdelivery age at test may not adequately predict infants with diminished sweating capacity. Corrected age at test, defined by summing gestational age and postdelivery age at time of test, should be considered when determining the appropriate time to perform a sweat test. Waiting until preterm infants screening positive for $\mathrm{CF}$ reach 39 weeks of age prior to sweat testing will reduce the
QNS rate and associated repeat sweat tests. Further research is necessary to evaluate the potential impact of delays in treatment due to implementation of this recommendation.

\section{ACKNOWLEDGMENTS}

We would like to acknowledge the Michigan Newborn Screening Cystic Fibrosis Advisory Council and Research Subcommittee for their support of this project.

\section{REFERENCES}

1. Welsh MJ, Ramsy BW, Accurso F, Cutting GR. Cystic fibrosis. In: Scriver CR, Beaudet AL, Sly WS, Valle D, editors. The metabolic and molecular basis of inherited disease, 8th edition. New York, NY: McGraw-Hill; 2001. pp 5121-5188.

2. Farrell PM, Kosorok MR, Laxova A, Shen G, Koscik RE, Bruns WT, Splaingard M, Mischler EH. Nutritional benefits of neonatal screening for cystic fibrosis. N Engl J Med 1997;337:963-969.

3. Farrell PM, Kosorok MR, Rock MJ, Laxova A, Zeng L, Lai H, Hoffman G, Laessig RH, Splaingard ML. Early diagnosis of cystic fibrosis through neonatal screening prevents severe malnutrition and improves long-term growth. Pediatrics 2001; 107:1-13.

4. Lee DS, Rosenberg MA, Peterson A, Makholm L, Hoffman G, Laessig RH, Farrell PM. Analysis of the costs of diagnosing cystic fibrosis with a newborn screening program. J Pediatr 2003;142:617-623.

5. Grosse SD, Boyle CA, Botkin JR, Comeau AM, Kharrazi M, Rosenfeld M, Wilfond BS, CDC. Newborn screening for cystic fibrosis: evaluation of benefits and risks and recommendations for state newborn screening programs. MMWR Recomm Rep 2004; 53:1-36.

6. Watson MS, Mann MY, Lloyd-Puryear MA, Rinaldo P, Howell RR. Newborn screening: toward a uniform screening panel and system-executive summary. Pediatrics 2006;117:S296-S307.

7. Di Sant'Agnese PA, Darling RC, Perera GA, Shea E. Abnormal electrolyte composition of sweat in cystic fibrosis of the pancreas. Pediatrics 1953;12:549-563.

8. Gibson LE, Cooke RE. A test for concentration of electrolytes in sweat in cystic fibrosis of the pancreas utilizing pilocarpine by iontophoresis. Pediatrics 1959;23:545-549.

9. Farrell PM, Rosenstein BJ, White TB, Accurso FJ, Castellani C, Cutting GR, Durie PR, LeGrys VA, Massie J, Parad RB, Rock MJ, Campbell PW. Guidelines for diagnosis of cystic fibrosis in newborns through older adults: cystic fibrosis foundation consensus report. J Pediatr 2008;153:S4-S14.

10. Eng W, LeGrys VA, Schechter MS, Laughon MM, Barker PM. Sweat-testing in preterm and full-term infants less than 6 weeks of age. Pediatr Pulmonol 2005;40:64-67.

11. LeGrys VA. Sweat testing for cystic fibrosis: profiles of patients with insufficient samples. Clin Lab Sci 1993;6:73-74.

12. Cystic Fibrosis Foundation Center Committee. Sweat Testing Standards for CFF Accredited Care Centers. December 2009.

13. Farrell PM, Koscik RE. Sweat chloride concentrations in infants homozygous or heterozygous for $\mathrm{F}_{508}$ cystic fibrosis. Pediatrics 1996;97:524-528.

14. Taccetti G, Festini F, Braccini G, Campana S, de Martino M. Sweat testing in newborns positive to neonatal screening for cystic fibrosis. Arch Dis Child Fetal Neonatal Ed 2004;89:F463F464.

15. Parad RB, Comeau AM, Dorkin HL, Dovey M, Gerstle R, Martin T, O'Sullivan BP. Sweat testing infants detected by cystic fibrosis newborn screening. J Pediatr 2005;147:S69-S72. 
16. Hammond KB, Turcios NL, Gibson LE. Clinical evaluation of the Macroduct sweat collection system and conductivity analyzer in the diagnosis of cystic fibrosis. J Pediatr 1994;124:255260.

17. National Committee for Clinical Laboratory Standards. Sweat testing. Sample collection and quantitative analysis; approved guideline (document C34-A2). Wayne, PA: National Committee for Clinical Laboratory Standards; 2000.

18. Korzeniewski SJ, Grigorescu V, Copeland G, Gu G, Thoburn KK, Rogers JD, Young WI. Methodological innovations in data gathering: newborn screening linkage with live births records, Michigan, 1/2007-3/2008. Matern Child Health J 2010;14:360364.

19. DiGiuseppe DK, Aron DC, Ranbom L, Harper DL, Rosenthal GE. Reliability of birth certificate data: a multi-hospital comparison to medical records information. Matern Child Health J 2002;6: $169-179$.
20. Harpin VA, Rutter N. Sweating in preterm babies. J Pediatr 1982;100:614-619.

21. Bray PT, Clark GCF, Moody GJ, Thomas G, Thomas JDR. Sweat testing for cystic fibrosis: diagnostic screening with a combination chloride ion-selective electrode. Arch Dis Child Childhood 1978;53:483-486.

22. Amiel-Tison C, Maillard F, LeBrun F, Breart G, Papiernik E. Neurological and physical maturation in normal growth singletons from 37 to 41 weeks gestation. Early Hum Dev 1999;54: $145-156$.

23. Longin E, Gerstner T, Schaible T, Lenz T, Konig S. Maturation of the autonomic nervous system: differences in heart rate variability in premature vs. term infants. J Perinat Med 2006;34:303-308.

24. Masafumi M, Tadayoshi H, Yoko S, Kenji S, Akari K, Toshio Y. Development of autonomic nervous system of preterm, low-birth weight infants evaluated by frequency analysis of heart rate variability. Acta Neurol Jpn 2003;39:511-518. 